OPEN ACCESS

Edited by:

Elnara Shafiyeva,

Baku State University, Azerbaijan

Reviewed by:

lqbal Pramukti,

Padjadjaran University, Indonesia

Xiuli Song,

Yantai Affiliated Hospital of Binzhou

Medical University, China

*Correspondence:

Li Weihui

weihui_li@csu.edu.cn

tThese authors have contributed equally to this work and share first

authorship

Specialty section

This article was submitted to Public Mental Health, a section of the journal Frontiers in Psychiatry

Received: 01 May 2021 Accepted: 17 June 2021 Published: 19 July 2021

Citation:

Lizhi X, Peng C, Wanhong Z,

Shengmei $X$, Lingjiang $L, L i Z$,

Xiaoping $W$ and Weihui $L$ (2021) Factors Associated With Preference of Psychological Intervention and Mental

Status Among Chinese Teachers During Coronavirus Disease 2019: A

Large Cross-Sectional Survey.

Front. Psychiatry 12:704010. doi: 10.3389/fpsyt.2021.704010

\section{Factors Associated With Preference of Psychological Intervention and Mental Status Among Chinese Teachers During Coronavirus Disease 2019: A Large Cross-Sectional Survey}

\author{
Xu Lizhi ${ }^{1,2,3+}$, Cheng Peng ${ }^{1,2,3+}$, Zheng Wanhong ${ }^{4}$, Xu Shengmei ${ }^{5}$, Li Lingjiang ${ }^{1,2,3}$, \\ Zhang Li ${ }^{1,2,3}$, Wang Xiaoping ${ }^{1,2,3}$ and Li Weihui ${ }^{1,2,3 *}$
}

${ }^{1}$ Department of Psychiatry, Second Xiangya Hospital, Central South University, Changsha, China, ${ }^{2}$ Mental Health Institute, Second Xiangya Hospital, Central South University, Changsha, China, ${ }^{3}$ Key Laboratory of Psychiatry and Mental Health of Hunan, Central South University, Changsha, China, ${ }^{4}$ Department of Behavioral Medicine and Psychiatry, West Virginia University, Morgantown, WW, United States, ${ }^{5}$ University of Illinois, Urbana-Champaign, Champaign, IL, United States

\begin{abstract}
Aims: The authors sought to explore the psychological distress of teachers during COVID-19 pandemic and their preference for psychological intervention. The overarching goal was to gain insight on how to build an effective psychological support system for teachers during and after the pandemic.
\end{abstract}

Methods: The mental health condition of teachers $(N=18,521)$ was assessed online by using a questionnaire consisting of standard instruments PHQ-15, GAD-7, PHQ-2, PC-PTSD, and additional questions about sleep disturbance, suicidality and preference of psychological intervention methods.

Results: $35.5 \%$ of Chinese teachers reported sleep disturbance, 25.3\% complained somatic discomfort, $17.7 \%$ had anxiety symptoms, $4.0 \%$ had depression, $2.8 \%$ had self-injury or suicidal thoughts. Women are more likely to have somatic symptoms, sleep disturbance and depression. There were age differences for anxiety, somatic symptoms and suicidal thoughts. High percentages of university teachers reported moderate to severe anxiety, somatic symptoms, depression and sleep disturbance. The most preferred psychological intervention is the self-practice of stress management skills $(N=11,477,62.0 \%)$. Teachers with moderate and severe symptoms are more likely in need of hotline and online counseling and those with serious suicidal thoughts are three times more likely to use a telephone hotline.

Conclusions: During the COVID-19 outbreak, the major reported psychological distresses among Chinese teachers are anxiety, sleep disturbance and somatic symptoms. There were gender, age and school setting differences. Females, teachers over 45 years old and those who work at universities tend to be more vulnerable. Different teachers chose different interventions, mostly based on the severity of their symptoms.

Keywords: teachers, mental health, COVID-19, psychological intervention, anxiety, sleep disturbance 


\section{INTRODUCTION}

Many studies have demonstrated a clear linkage between major infectious disease outbreak and its impact on mental health. For example, the outbreak of Severe Acute Respiratory Syndrome (SARS) in 2003 led to significantly increased number of mental illness cases and prolonged courses. A survey found that $38.9 \%$ of general population were worried about health problems caused by SARS, among which women and people with low education reported higher level of anxiety (1).

The COVID-19 has caused a worldwide pandemic that affected every aspect of human lives. The new pathogen was found to be more infectious than SARS-CoV (2). Many countries have started different measures to mitigate the transmission of the virus. Most public services including schools have to be closed and people are encouraged or required to do social distancing and home isolation. While stringent measures to keep people apart can slow the spread of the virus, they may come with significant mental health cost. One study during the SARS period found that among faculty and students quarantined in Beijing, $24.6 \%$ met diagnostic criteria for psychiatric disorders during the quarantine, and $26.2 \%$ had problems 8 months after the quarantine ended (3). Of the 129 citizens voluntarily quarantined in Toronto, $28.9 \%$ experienced symptoms of post-traumatic stress disorder (PTSD) and 31.2\% had depression.

Teaching is a stressful and challenging profession. During this pandemic time, in addition to isolation, teachers have to adapt to many other changes that could potentially make them more vulnerable to psychological distress. The impact of COVID-19 and school closure on the mental health of teachers is unclear but warrants research. This is not only because of the importance of teachers in our society but also due to the comparative influence of teachers on students and parents. Researches show that teachers' stress and negative emotions can lead to poor classroom performance (4) and affect their ability to properly support and respond to students (5). The so-called teacher-oriented teaching model, that is, teachers play the role of classroom lecturers, presenting information directly to students, and the subsequent high pressure on Chinese teachers make this population unique from those of other countries. The present study aims to understand the psychological distress of Chinese teachers during COVID-19 pandemic and their preference for psychological intervention. The overarching goal was to gain insight on how to build an effective psychological support system for teachers during and after the pandemic.

\section{MATERIALS AND METHODS}

The data of this study were obtained through an online questionnaire. A hyperlink was distributed via WeChat social media platform and emails. The completion of the survey was voluntary and anonymous. After submission, the participants were given a choice to download electronic copies of some psychology educational materials, audio instructions for stress management, as well as a list of professional hotline and online counseling services. The study was approved by the
Ethics Committee of the Second Xiangya Hospital of Central South University.

\section{Participants}

The survey was online distributed to teachers of kindergartens, primary schools, middle/high schools and universities in Changsha on February 21 and officially closed on February 29, 2020. 18,521 teachers fully read and signed the online informed consent form before filling out the questionnaire, and voluntarily participates in the survey. As the survey was posted online, only those who completed the questionnaire and clicked the submission were counted. We were not able to collect data on incomplete responses. The survey was conducted in Changsha, Hunan Province because the number of schools and universities in Changsha allowed a huge sample size and the strong support from the Changsha Municipal Bureau of Education provided convenience for the survey distribution and data collection.

\section{Questionnaire Measures}

The questionnaire of this study is a combination of four standard self-administered instruments and some customized specific questions.

We used PHQ-2 for assessment of depression. The cut-off score for significant clinical symptoms is 3 (6). GAD-7 was used to screen anxiety. Cutoff points 5, 10 and 15 represent mild, moderate and severe level of anxiety symptoms $(7,8)$. PHQ-15 was included for measuring the severity of somatic symptoms (9). The cutoff scores of 5,10 and 15 are used for mild, moderate and severe level of somatization (6). For PTSD, we used PCPTSD-5. A cut-off score of 4 is used in this study because of the reported well-balanced specificity and sensitivity therefore maximal efficiency (10).

We added two items to screen for sleep, self-injury and suicidal ideation. Item 9 of PHQ-9 was used to screen selfinjury and suicidal ideation in the past 2 weeks. Another separate sleep item also from PHQ-9 asks subjects having difficulty falling asleep or restless or sleeping too much in the past 2 weeks. This item can be used for a wide range of sleep screening, and its performance is comparable to Insomnia Severity Index (ISI) (11). Last, we included a question about preference for psychological intervention. Four choices were given: self-care and self-reading of psychology materials, self-adjustment (stress management skills), telephone hotline, and online psychological counseling. The reason for choosing these interventions is because at the beginning of the epidemic, our mental health center has compiled a list of professional e-books, set up a telephone hotline and launched an online consultation platform. Those had become easily accessible to the public at the time of this survey. Also the previous experiences of using telephone hotline and online services in major disasters support the usability and applicability of these two approaches in the current pandemic $(12,13)$.

\section{Statistical Analysis}

Descriptive statistics were used to explore the demographic characteristics of the participants, the frequency, concentration trend of psychological symptoms. The severity of symptoms was distinguished according to the scores of different scales. 
TABLE 1 | Demographic characteristics $(N=18,521)$.

\begin{tabular}{lc}
\hline Sex $\boldsymbol{N}$ (\%) & \\
\hline Male & $3,909(21.1 \%)$ \\
Female & $14,612(78.9 \%)$ \\
School Setting $\boldsymbol{N}$ (\%) & \\
Kindergarten & $1,436(7.8 \%)$ \\
Primary School & $9,764(52.7 \%)$ \\
Middle/High School & $6,994(37.8 \%)$ \\
University & $327(1.8 \%)$ \\
Age $N$ (\%) & \\
$\leq 25$ & $3,023(16.3 \%)$ \\
$26-35$ & $7,269(39.2 \%)$ \\
36-45 & $4,364(23.6 \%)$ \\
$>45$ & $3,865(20.9 \%)$ \\
Education $\boldsymbol{N}$ (\%) & \\
Associate Degree & $2,937(15.9)$ \\
Bachelor's Degree & $14,178(76.6)$ \\
Master's Degree & $1,342(7.2)$ \\
Doctor's Degree & $64(0.3 \%)$ \\
Surrounding risk of infection $\boldsymbol{N}$ (\%) & \\
Staying at home with family & $17,246(93.1 \%)$ \\
Home Isolation from family & $1,062(5.7 \%)$ \\
Active volunteering & $90(0.5 \%)$ \\
Confirmed infection, in treatment & $6(<0.1 \%)$ \\
Suspected infection, in quarantine & $1(<0.1 \%)$ \\
\hline
\end{tabular}

The detection rates were counted by percentages. Chi-square tests were used to analyze the possible relationship between the incidence of different degrees of symptoms and the characteristics of patients. A Post hoc analysis is performed when the chi-square test finds a statistical significance. We calculated the Adjusted Standardized Residuals (ASR) to find out which cells in the contingency table are different from their expected values. The larger the ASR, the greater the contribution of these residuals to the overall chi-square test. To estimate more conservatively, we chose to limit the absolute value of the ASR to 3 (42). When it is over 3, we think that there is a statistically significant difference between the observed and the expected frequency.

\section{RESULTS}

\section{Demographic Characteristics}

A total of 18,521 people responded to the survey. Table 1 summarizes the demographic characteristics. $78.9 \%$ of participants are women, which is consistent with the gender distribution of teaching profession in China. Over $90 \%$ are elementary, middle/high school teachers, which are the main targeted population of this study. Among the four age groups, 26 to 35 years old accounts for the highest proportion (39.2\%). For educational background, most have undergraduate degrees (76.6\%). While $93.1 \%$ teachers were living with family at home, $5.7 \%$ reported home isolation from other family members, a few were active volunteers in COVID-19 taskforce, 6 had confirmed COVID-19 infection, 1 had suspected infection. Also, $763(4.1 \%)$ participants reported flu-like symptoms or other general physical discomfort that were not caused by COVID-19. Of all subjects, only $122(0.07 \%)$ reported known exposure to COVID-19 infection.

\section{Prevalence Rates of Anxiety, Depression, Somatic Symptoms, PTSD, Suicidal Thoughts, and Sleep Disturbance}

Figure 1 shows $17.7 \%$ of teachers scored $\geq 5$ (at least mild anxiety) on GAD-7, of which $4.2 \%$ reported moderate to severe anxiety (GAD-7 score $\geq 10$ ). For depression, 4.0\% had PHQ-2 score $\geq 3$, interpreted as having significant clinical depression. $25.3 \%$ teachers scored $\geq 5$ on PHQ-15 for somatic discomfort, among which $5.5 \%$ had moderate and $1.5 \%$ had severe symptoms. Sleep, general fatigue and back pain were the three most frequently reported somatic discomforts. The high level of sleep complaint was self-validated by a separate sleep item, for which $35.5 \%$ reported sleep disturbance for a few days to almost every day. Surprisingly, only $0.5 \%$ teachers scored $\geq 4$ on PC-PTSD scale. The number of people with suicidal thoughts or self-injury accounted for $2.8 \%$ of the total population. Among these, $0.3 \%$ reported having suicidal thoughts more than half of the days in the past 2 weeks and $0.2 \%$ almost every day.

\section{Correlation Analysis}

Table 2 summaries the correlation analysis between demographic characteristics and scores of GAD-7, PHQ-15, and PHQ-2. We divided the subjects into two groups: no to mild symptom group, and moderate to severe symptom group. For anxiety, there were significant differences between these two groups in terms of age $\left(\mathrm{X}^{2}=93.72, P<0.001\right)$ and school section $\left(\mathrm{X}^{2}\right.$ $=38.83, P<0.001)$. Teachers over 45 years old $($ ASR $=7.7)$ and those who work in universities (ASR $=4.7)$ were more likely to have moderate to severe anxiety symptoms. While gender and education did not seem to have an association with the severity of anxiety symptoms, it is not true for somatic complaints. $7.6 \%$ of the female teachers reported moderate to severe somatic discomfort, which was statistically higher than their male counterparts (4.9\%). The higher education, the more likely the teacher will report somatic discomfort. The same trend was noticed in age and school section where teachers work. 8.5\% of the teachers over 45 years old (ASR $=4.0$ ) and $12.8 \%$ of university teachers $(\mathrm{ASR}=4.1)$ reported moderate to severe somatic symptoms. To our surprise, none of the six patients with confirmed infection reported severe physical discomfort (data not shown). For depression, more females had moderate to severe symptoms ( $\mathrm{X}^{2}=8.447, P<0.01$ ). Again, higher percentage $(8.6 \%)$ of university teachers endorsed moderate to severe depression. Chi-square showed no statistical difference in depression severity in terms of age and education background.

To analyze the correlation of suicidal thoughts and sleep disturbance with demographics, we separated subjects into two groups using symptom duration of half of the days as threshold (Table 3). Age is the only known factor associated 


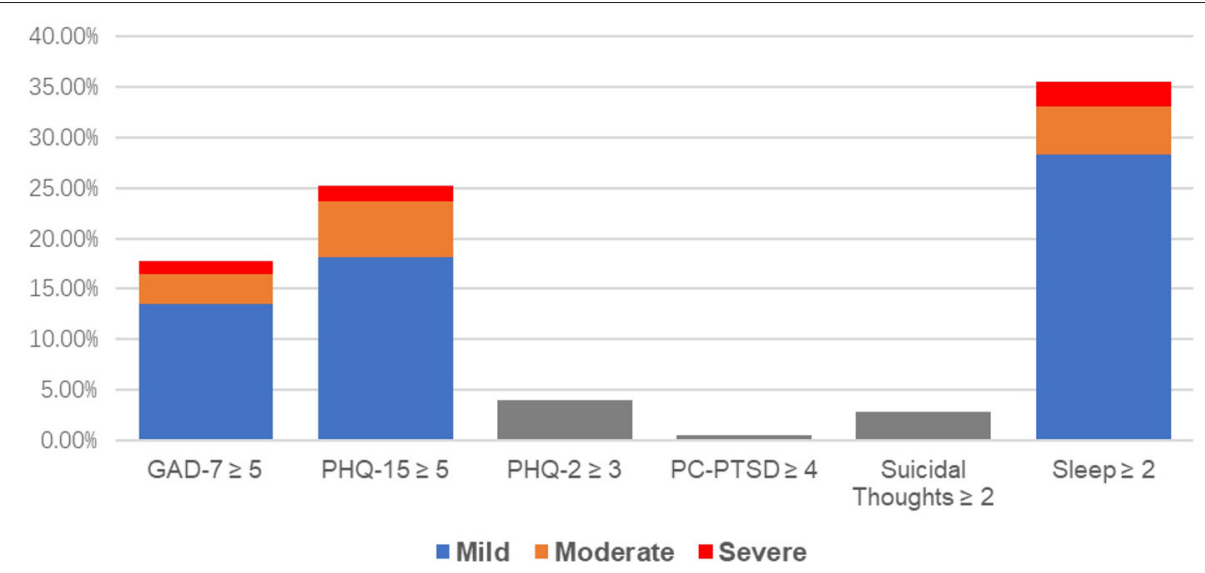

FIGURE 1 | Prevalence rates for symptomatic ratings. 1. For GAD-7 and PHQ-15 the cutting score is 5. 2. For PHQ-2 the cutting score is 3. 3. For PC-PTSD the cutting score is 4. 4. For Suicidal thoughts and Sleep, symptomatic means at least "more than half of the days" in the past 2 weeks.

with the severity of suicidal thoughts $\left(\mathrm{X}^{2}=12.22, P<0.01\right)$. Teachers younger than 25 and above 45 are more likely to have severe suicidal thoughts than those in between. For sleep disturbance, there were statistical differences among different genders, education backgrounds, and school sections. More women complained about serious sleep problem. So do university teachers and those with $\mathrm{PhD}$ degrees.

\section{Preference of Psychological Intervention}

The most preferred psychological intervention is the practice of stress management skills (62.0\%). 32.3\% teachers would like to download and read psychology education materials, $5.1 \%$ preferred to use telephone hotline, and $19.1 \%$ thought they needed online psychological counseling. Table 4 shows the Chisquare analysis of symptomology and treatment preference. Individuals with non to mild symptoms seem to be satisfied with both psychology reading materials and stress management skills; those with moderate and severe symptoms are more likely in need of hotline and online counseling. For anxiety, somatic discomfort, depression and sleep disturbance, teachers with moderate to severe problems are more likely to choose an external intervention. For PTSD, 62\% of asymptomatic and $63.5 \%$ of symptomatic teachers chose stress management skills but there was no difference between two groups. For suicidal thoughts, the only association found was for telephone hotline use. Teachers with serious suicidal thoughts are three times more likely to use telephone hotline $\left(\mathrm{X}^{2}=25.29, P\right.$ $\leq 0.001)$. This difference was not detected for other types of interventions.

Also, more male teachers chose self-care and self-reading of psychological materials (35.5\% vs. $31.4 \%$ ), telephone hotline (6.3\% vs. $4.8 \%)$, and online counseling (20.3\% vs. $18.8 \%)$. To the opposite, significantly more females $(62.8 \%$ vs. $20.0 \%, P \leq 0.001)$ preferred stress management skills. We also found that telephone hotline service and online counseling were preferred choices of teachers between 26 and 35 comparing with other age groups, and the former was also more liked by those who teach in the middle and high school settings.

\section{DISCUSSION}

The main purpose of this study is to examine the mental health impact of COVID-19 pandemic on Chinese teachers during school closure time. There are several findings in this study. First, of all teachers surveyed, more than $1 / 4(25.3 \%)$ had mild or more somatic discomfort, $1 / 6(17.7 \%)$ had mild to severe anxiety, only $4.0 \%$ reported clinically significant depression. This ratio is lower than the $34 \%$ anxiety and severe anxiety and $8 \%$ severe depression reported by the survey of middle school teachers at the beginning of the Greek pandemic (14). As study has found that Chinese patients with depression are more likely to report feelings of fatigue and muscle aches instead of psychological symptoms $(15,16)$, under-report of depression in this population cannot be ruled out. Comparing with $9.3 \%$ occurrence rate of the general population (17), high level of anxiety may be related to the high infectivity of COVID-19 and the rapid information exchange under modern social media technology. During the SARS outbreak in 2003, some studies pointed out that the level of anxiety was closely related to the intensity of the outbreak and the number of new cases every day (18). This pandemic is the first major one in the social media age. Early and quick epidemiological analysis proved that the spread of $2019-\mathrm{nCoV}$ is much faster than previous outbreaks of SARS-CoV and MERS$\mathrm{CoV}$ (2). This and other coronavirus related information, both true and false, were quickly shared on the Internet and various social media platforms. Human takes cues and feedbacks from each other. The society's perception and response to a disaster like COVID-19 can be easily changed by publicized information. The unprecedented myriad real-time postings on social media, including the rapidly growing cases every day, can undoubtedly increase public anxiety and frustration. Additionally, from the beginning of this crisis, so-called draconian quarantine measures against the novel coronavirus limited people's normal social contact, which may also be closely related to the emergence of anxiety among the studied population (19).

Second, sleep disturbance, general fatigue and back pain were the three most frequently reported somatic symptoms in 
TABLE 2 | Demographic and GAD-7, PHQ-15, PHQ-2, Chi-square analysis.

\begin{tabular}{|c|c|c|c|c|c|c|c|c|c|}
\hline \multirow[b]{2}{*}{ Demographic Characteristics } & \multicolumn{2}{|c|}{ Anxiety symptoms* } & \multirow[t]{2}{*}{$\chi^{2}$ (df) } & \multicolumn{2}{|c|}{ Somatic Symptoms ${ }^{\star *}$} & \multirow[t]{2}{*}{$\chi^{2}(\mathrm{df})$} & \multicolumn{2}{|c|}{ Depressive symptoms ${ }^{\star \star \star}$} & \multirow[t]{2}{*}{$\chi^{2}(\mathrm{df})$} \\
\hline & $\begin{array}{l}\text { Non to mild } \\
N=17,735\end{array}$ & $\begin{array}{l}\text { Moderate to } \\
\text { severe } \\
N=786\end{array}$ & & $\begin{array}{l}\text { Non to mild } \\
N=17,218\end{array}$ & $\begin{array}{l}\text { Moderate to } \\
\text { severe } \\
N=1,303\end{array}$ & & $\begin{array}{l}\text { Asymptomatic } \\
N=17,784\end{array}$ & $\begin{array}{c}\text { Symptomatic } \\
N=737\end{array}$ & \\
\hline Sex & & & $1.54(1)$ & & & 34.16 (1) § & & & $8.45(1) \ddagger$ \\
\hline Men, $N(\%)$ & $3,757(96.1)$ & $152(3.9)$ & & $3,717(95.1)$ & $192(4.9)$ & & 3,785 (96.8) & $124(3.2)$ & \\
\hline $\mathrm{ASR}^{\star \star \star \star}$ & 1.2 & -1.2 & & 5.8 & -5.8 & & 2.9 & -2.9 & \\
\hline Women, $N(\%)$ & $13,978(95.7)$ & $634(4.3)$ & & $13,501(92.4)$ & $1,111(7.6)$ & & 13,999 (95.8) & $613(4.2)$ & \\
\hline ASR & -1.2 & 1.2 & & -5.8 & 5.8 & & -2.9 & 2.9 & \\
\hline Age (y) & & & $93.72(3) \S$ & & & $29.20(3) \S$ & & & $5.28(3)$ \\
\hline$\leq 25, N(\%)$ & 2,954 (97.7) & $69(2.3)$ & & $2,856(94.5)$ & $167(5.5)$ & & 2,893 (95.7) & $130(4.3)$ & \\
\hline ASR & 5.8 & -5.8 & & 3.6 & -3.6 & & -1.0 & 1.0 & \\
\hline $26-35, N(\%)$ & 7,020 (96.6) & $249(3.4)$ & & 6,797 (93.5) & $472(6.5)$ & & 7,007 (96.4) & $262(3.6)$ & \\
\hline ASR & 4.4 & -4.4 & & 2.3 & -2.3 & & 2.1 & -2.1 & \\
\hline $36-45, N(\%)$ & $4,146(95.0)$ & $218(5.0)$ & & 4,028 (92.3) & $336(7.7)$ & & $4,189(96.0)$ & $175(4.0)$ & \\
\hline ASR & -2.8 & 2.8 & & -2.0 & 2.0 & & -0.1 & 0.1 & \\
\hline$>45, N(\%)$ & $3,615(93.5)$ & $250(6.5)$ & & $3,537(91.5)$ & $328(8.5)$ & & 3,695 (95.6) & $170(4.4)$ & \\
\hline ASR & -7.7 & 7.7 & & -4.0 & 4.0 & & -1.5 & 1.5 & \\
\hline Education & & & $7.60(3)$ & & & $9.88(3)^{\dagger}$ & & & $4.44(3)$ \\
\hline College, $N(\%)$ & $2,810(95.7)$ & $127(4.3)$ & & $2,765(94.1)$ & $172(5.9)$ & & 2,834 (96.5) & $103(3.5)$ & \\
\hline ASR & -0.2 & 0.2 & & 2.7 & -2.7 & & 1.4 & -1.4 & \\
\hline Undergraduate, N (\%) & $13,587(95.8)$ & $591(4.2)$ & & 13,163 (92.8) & $1,015(7.2)$ & & 13,602 (95.9) & $576(4.1)$ & \\
\hline ASR & 0.9 & -0.9 & & -1.2 & 1.2 & & -1.0 & 1.0 & \\
\hline Master Degree, $N(\%)$ & $1,281(95.5)$ & $61(4.5)$ & & $1,232(91.8)$ & $110(8.2)$ & & $1,289(96.1)$ & $53(3.9)$ & \\
\hline ASR & -0.6 & 0.6 & & -1.7 & 1.7 & & 0.1 & -0.1 & \\
\hline Ph.D., N (\%) & $57(89.1)$ & $7(10.9)$ & & $58(90.6)$ & $6(9.4)$ & & $59(92.2)$ & $5(7.8)$ & \\
\hline ASR & -2.7 & 2.7 & & -0.7 & 0.7 & & -1.6 & 1.6 & \\
\hline School section & & & $38.83(3) \S$ & & & $27.72(3) \S$ & & & $37.45(3) \S$ \\
\hline Kindergarten, $N(\%)$ & $1,388(96.7)$ & $48(3.3)$ & & $1,360(94.7)$ & $76(5.3)$ & & $1,376(95.8)$ & $60(4.2)$ & \\
\hline ASR & 1.8 & -1.8 & & 2.7 & -2.7 & & -0.4 & 0.4 & \\
\hline Primary school, $N(\%)$ & $9,400(96.3)$ & $364(3.7)$ & & 9,107 (93.3) & $657(6.7)$ & & $9,440(96.7)$ & 324 (3.3) & \\
\hline ASR & 3.7 & -3.7 & & 1.7 & -1.7 & & 4.9 & -4.9 & \\
\hline Middle school, $N(\%)$ & $6,651(95.1)$ & $343(4.9)$ & & 6,466 (92.5) & $528(7.5)$ & & 6,669 (95.4) & $325(4.6)$ & \\
\hline ASR & -3.5 & 3.5 & & -2.1 & 2.1 & & -3.6 & 3.6 & \\
\hline University, $N(\%)$ & 296 (90.5) & $31(9.5)$ & & $285(87.2)$ & $42(12.8)$ & & $299(91.4)$ & $28(8.6)$ & \\
\hline ASR & -4.7 & 4.7 & & -4.1 & 4.1 & & -4.3 & 4.3 & \\
\hline
\end{tabular}

${ }^{*}$ The scores of $G A D-7<5, \geq 5, \geq 10$, and $\geq 15$ represent non, mild, moderate, and severe anxiety symptoms, respectively.

${ }^{* *}$ The scores of PHQ-15 $<5, \geq 5, \geq 10$, and $\geq 15$ represent non, mild, moderate, and severe somatic symptoms, respectively.

${ }^{* * *} P H Q-2$ score $\geq 3$ indicates clinically significant depressive symptoms.

${ }^{\star * \star * A d j u s t e d ~ S t a n d a r d i z e d ~ R e s i d u a l s . ~ T h e ~ l a r g e r ~ t h e ~ A S R, ~ t h e ~ l a r g e r ~ t h e ~ c o n t r i b u t i o n ~ o f ~ t h e ~ c e l l ~ t o ~ t h e ~ o v e r a l l ~ c h i-s q u a r e ~ t e s t . ~ W e ~ s e t ~} \pm 3$ as a significant difference.

${ }^{\dagger} p \leq 0.05, \neq p \leq 0.01, \S p \leq 0.001$. 
TABLE 3 | Demographic and Sleep disturbance and Suicidal thoughts, Chi-square analysis.

\begin{tabular}{|c|c|c|c|c|c|c|}
\hline \multirow[b]{2}{*}{$\begin{array}{l}\text { Demographic } \\
\text { Characteristics }\end{array}$} & \multicolumn{2}{|c|}{ Sleep disturbance* } & \multirow[t]{2}{*}{$\chi^{2}$ (df) } & \multicolumn{2}{|c|}{ Suicidal thoughts ${ }^{* *}$} & \multirow[t]{2}{*}{$\chi^{2}$ (df) } \\
\hline & $\begin{array}{c}\text { Non or less } \\
\text { than half of } \\
\text { the days } \\
N=17,193\end{array}$ & $\begin{array}{c}\text { Over half of } \\
\text { the days } \\
N=1,328\end{array}$ & & $\begin{array}{c}\text { Non or less } \\
\text { than half of } \\
\text { the days } \\
N=18,422\end{array}$ & $\begin{array}{l}\text { Over half of } \\
\text { the days } \\
N=99\end{array}$ & \\
\hline Sex & & & 24.76 (3) § & & & $0.00(1)$ \\
\hline Men, $N(\%)$ & $3,700(94.7)$ & $209(5.3)$ & & 3,888 (99.5) & $21(0.5)$ & \\
\hline $\mathrm{ASR}^{\star \star \star}$ & 5.0 & -5.0 & & 0.0 & 0.0 & \\
\hline Women, $N(\%)$ & $13,493(92.3)$ & $1,119(7.7)$ & & $14,534(99.5)$ & $78(0.5)$ & \\
\hline ASR & -5.0 & 5.0 & & 0.0 & 0.0 & \\
\hline Age (y) & & & $2.74(3)$ & & & $12.22(3) \ddagger$ \\
\hline$\leq 25, N(\%)$ & 2,797 (92.5) & $226(7.5)$ & & 3,003 (99.3) & $20(0.7)$ & \\
\hline ASR & -0.7 & 0.7 & & -1.0 & 1.0 & \\
\hline 26-35, N (\%) & 6,760 (93.0) & $509(7.0)$ & & 7,244 (99.7) & $25(0.3)$ & \\
\hline ASR & 0.7 & -0.7 & & 2.9 & -2.9 & \\
\hline 36-45, N (\%) & 4,066 (93.2) & $298(6.8)$ & & 4,342 (99.5) & $22(0.5)$ & \\
\hline ASR & 1.0 & -1.0 & & 0.3 & -0.3 & \\
\hline$>45, N(\%)$ & $3,570(92.4)$ & 295 (7.6) & & 3,833 (99.2) & $32(0.8)$ & \\
\hline ASR & -1.3 & 1.3 & & -2.8 & 2.8 & \\
\hline Education & & & $11.67(3) \ddagger$ & & & $3.39(3)$ \\
\hline College, $N(\%)$ & 2,738 (93.2) & $199(6.8)$ & & 2,918 (99.4) & $19(0.6)$ & \\
\hline ASR & 0.9 & -0.9 & & -0.9 & 0.9 & \\
\hline Undergraduate, $N(\%)$ & $13,167(92.9)$ & $1,011(7.1)$ & & $14,103(99.5)$ & $75(0.5)$ & \\
\hline ASR & 0.4 & -0.4 & & 0.2 & -0.2 & \\
\hline Master Degree, $N(\%)$ & $1,235(92.0)$ & $107(8.0)$ & & 1,338 (99.7) & $4(0.3)$ & \\
\hline ASR & -1.2 & 1.2 & & 1.2 & -1.2 & \\
\hline Ph.D., N (\%) & $53(82.8)$ & $11(17.2)$ & & $63(98.4)$ & $1(1.6)$ & \\
\hline ASR & -3.1 & 3.1 & & -1.1 & 1.1 & \\
\hline School section & & & 36.80 (3) § & & & $2.02(3)$ \\
\hline Kindergarten, $N(\%)$ & 1,349 (93.9) & $87(6.1)$ & & $1,431(99.7)$ & $5(0.3)$ & \\
\hline ASR & 1.7 & -1.7 & & 1.0 & -1.0 & \\
\hline Primary school, $N(\%)$ & $9,049(92.7)$ & $715(7.3)$ & & 9,715 (99.5) & $49(0.5)$ & \\
\hline ASR & -0.8 & 0.8 & & 0.6 & -0.6 & \\
\hline Middle school, $N(\%)$ & 6,518 (93.2) & $476(6.8)$ & & 6,951 (99.4) & $43(0.6)$ & \\
\hline ASR & 1.5 & -1.5 & & -1.2 & 1.2 & \\
\hline University, N (\%) & $277(84.7)$ & $50(15.3)$ & & $325(99.4)$ & $2(0.6)$ & \\
\hline ASR & -5.7 & 5.7 & & -0.2 & 0.2 & \\
\hline
\end{tabular}

"The sleep item asked the subjects how many days they had a problem of "difficulty falling asleep, difficulty sleeping, or excessive sleep" in the past 2 weeks.

**The sleep item asked the subjects how many days they had self-harm or suicidal thoughts in the past 2 weeks.

${ }^{* \star *}$ Adjusted Standardized Residuals. The larger the ASR, the larger the contribution of the cell to the overall chi-square test. We set \pm 3 as a significant difference.

${ }^{+} p \leq 0.05, \neq p \leq 0.01, \S p \leq 0.001$. 
TABLE 4 | The association between Treatment preference and GAD-7, PHQ-15, PHQ-2, SI, Sleep disturbance Chi-square analysis.

\begin{tabular}{|c|c|c|c|c|c|c|c|c|c|c|c|c|}
\hline & \multicolumn{2}{|c|}{ Psychological materials ${ }^{*}$} & \multirow[t]{2}{*}{$\chi^{2}(\mathrm{df}=1)$} & \multicolumn{2}{|c|}{ Stress management skills ${ }^{* *}$} & \multirow[t]{2}{*}{$\chi^{2}(d f=1)$} & \multicolumn{2}{|c|}{ Telephone hotline } & \multirow[t]{2}{*}{$\chi^{2}(\mathrm{df}=1)$} & \multicolumn{2}{|c|}{ Online psychological counseling } & \multirow[t]{2}{*}{$\chi^{2}(d f=1)$} \\
\hline & $\begin{array}{l}\text { No need } \\
N=12,545\end{array}$ & $\begin{array}{l}\text { Need } \\
N=5,976\end{array}$ & & $\begin{array}{l}\text { No need } \\
N=7,044\end{array}$ & $\begin{array}{l}\text { Need } \\
N=11,477\end{array}$ & & $\begin{array}{l}\text { No need } \\
N=17,579\end{array}$ & $\begin{array}{l}\text { Need } \\
N=942\end{array}$ & & $\begin{array}{c}\text { No need } \\
N=14,989\end{array}$ & $\begin{array}{c}\text { Need } \\
N=3,532\end{array}$ & \\
\hline $\begin{array}{l}\text { Anxiety } \\
\text { symptoms }\end{array}$ & & & $5.61^{\dagger}$ & & & $51.89 \S$ & & & $50.95 \S$ & & & $20.76 \S$ \\
\hline Non to mild, $N(\%)$ & $12,043(67.9)$ & $5,692(32.1)$ & & $6,841(38.6)$ & 10,894 (61.4) & & $16,876(95.2)$ & $859(4.8)$ & & $14,402(81.2)$ & 3,333 (18.8) & \\
\hline $\mathrm{ASR}^{\star \star \star}$ & 2.4 & -2.4 & & 7.2 & -7.2 & & 7.1 & -7.1 & & 4.6 & -4.6 & \\
\hline $\begin{array}{l}\text { Moderate to } \\
\text { severe, } N(\%)\end{array}$ & $502(63.9)$ & $284(36.1)$ & & $203(25.8)$ & $583(74.2)$ & & $703(89.4)$ & $83(10.6)$ & & $587(74.7)$ & $199(25.3)$ & \\
\hline ASR & -2.4 & 2.4 & & -7.2 & 7.2 & & -7.1 & 7.1 & & -4.6 & 4.6 & \\
\hline Somatization & & & $11.67 \S$ & & & $77.31 \S$ & & & $53.11 \S$ & & & $38.21 \S$ \\
\hline Non to mild, $N(\%)$ & $11,718(68.1)$ & $5,500(31.9)$ & & 6,697 (38.9) & $10,521(61.1)$ & & $16,398(95.2)$ & $820(4.8)$ & & $14,019(81.4)$ & 3,199 (18.6) & \\
\hline ASR & 3.4 & -3.4 & & 8.8 & -8.8 & & 7.3 & -7.3 & & 6.2 & -6.2 & \\
\hline $\begin{array}{l}\text { Moderate to } \\
\text { severe, } N(\%)\end{array}$ & $827(63.5)$ & $476(36.5)$ & & $347(26.6)$ & $956(73.4)$ & & $1,181(90.6)$ & $122(9.4)$ & & $970(74.4)$ & $333(25.6)$ & \\
\hline ASR & -3.4 & 3.4 & & -8.8 & 8.8 & & -7.3 & 7.3 & & -6.2 & 6.2 & \\
\hline PTSD & & & $10.82 \S$ & & & 0.10 & & & $43.23 \S$ & & & $4.02^{\dagger}$ \\
\hline $\begin{array}{l}\text { Asymptomatic, N } \\
\text { (\%) }\end{array}$ & $12,495(67.8)$ & $5,930(32.2)$ & & $7,009(38.0)$ & $11,416(62.0)$ & & $17,502(95.0)$ & $923(5.0)$ & & $14,919(81.0)$ & 3,506 (19.0) & \\
\hline ASR & 3.3 & -3.3 & & 0.3 & -0.3 & & 6.6 & -6.6 & & 2.0 & -2.0 & \\
\hline $\begin{array}{l}\text { Possible PTSD, N } \\
(\%)\end{array}$ & $50(52.1)$ & $46(47.9)$ & & $35(36.5)$ & $61(63.5)$ & & $77(80.2)$ & $19(19.8)$ & & $70(72.9)$ & $26(27.1)$ & \\
\hline ASR & -3.3 & 3.3 & & -0.3 & 0.3 & & -6.6 & 6.6 & & -2.0 & 2.0 & \\
\hline $\begin{array}{l}\text { Depressive } \\
\text { symptoms }\end{array}$ & & & $10.98 \S$ & & & $36.76 \S$ & & & $58.01 \S$ & & & $32.36 \S$ \\
\hline $\begin{array}{l}\text { Asymptomatic, N } \\
\text { (\%) }\end{array}$ & $12,087(68.0)$ & $5,697(32.0)$ & & 6,842 (38.5) & $10,942(61.5)$ & & $16,924(95.2)$ & $860(4.8)$ & & 14,452 (81.3) & 3,332 (18.7) & \\
\hline ASR & 3.3 & -3.3 & & 6.1 & -6.1 & & 7.6 & -7.6 & & 5.7 & -5.7 & \\
\hline $\begin{array}{l}\text { Symptomatic, } N \\
\text { (\%) }\end{array}$ & 458 (62.1) & 279 (37.9) & & $202(27.4)$ & 535 (72.6) & & $655(88.9)$ & $82(11.1)$ & & $537(72.9)$ & $200(27.1)$ & \\
\hline ASR & -3.3 & 3.3 & & -6.1 & 6.1 & & -7.6 & 7.6 & & -5.7 & 5.7 & \\
\hline $\begin{array}{l}\text { Sleep } \\
\text { disturbance }\end{array}$ & & & $10.23 \S$ & & & $97.23 \S$ & & & $57.42 \S$ & & & $9.16 \ddagger$ \\
\hline $\begin{array}{l}<\text { half of the days, } \\
N(\%)\end{array}$ & $11,698(68.0)$ & 5,495 (32.0) & & 6,707 (39.0) & $10,486(61.0)$ & & $16,377(95.3)$ & $816(4.7)$ & & $13,956(81.2)$ & 3,237 (18.8) & \\
\hline ASR & 3.2 & -3.2 & & 9.9 & -9.9 & & 7.6 & -7.6 & & 3.0 & -3.0 & \\
\hline $\begin{array}{l}\geq \text { half of the days, } \\
N(\%)\end{array}$ & 847 (63.8) & 481 (36.2) & & 337 (25.4) & 991 (74.6) & & 1,202 (90.5) & $126(9.5)$ & & 1,033 (77.8) & $295(22.2)$ & \\
\hline ASR & -3.2 & 3.2 & & -9.9 & 9.9 & & -7.6 & 7.6 & & -3.0 & 3.0 & \\
\hline
\end{tabular}


teachers. This is consistent with many previous somatization studies $(17,20,21)$. The sleep complaint was also self-validated by a separate sleep item in the survey. Sleep is crucial to human life and closely related to emotion. Poor sleep is a risk factor for depression (22), anxiety (23), suicidal behavior (24), and PTSD symptoms (25). Long-term lack of sleep is also associated with fatigue and body aches, which in turn can lead to a decline in mental or physical functionality and be strong predictors of depression (26). Even though only $4.0 \%$ of the teachers interviewed had significant depressive symptoms, high prevalence of sleep problem and fatigue indicates more people could potentially escalate into clinical depression if untreated. Given the fact that both are important risk factors for suicidal thoughts and behavior, we can at least partially explain the reason why $2.8 \%$ of the respondents reported self-injury or suicidal thoughts. This study calls for a great attention to teachers' sleep needs and fatigue during COVID-19. At early stage, promoting good sleep hygiene and giving self-help tips to manage stress and fight overwhelming tiredness could be appropriate approach. Later on, clinical attention to the depression level of the teachers is certainly warranted.

Third, compared with $28.9 \%$ of PTSD symptoms among residents voluntarily quarantined in Toronto during SARS (27), and $24.55 \%$ of PTSD incidence among college teachers in Wuhan during COVID-19 (28), the rate was significantly lower in this survey. This may be related to the fact that this survey is done in Hunan, where the number of infections is relatively smaller than other major cities in China. Previous studies have shown that the occurrence of PTSD-related symptoms is related to the risk of virus exposure (29) and the fatality of the epidemic (30). The scientific data concerning the virus structure, transmission and epidemiology was quickly shared by the Chinese government after the outbreak. The lockdown of major cities like Wuhan and other mitigation measures helped people get better prepared, and may have increased their sense of control. All above plus early survey time could be the reasons for the low PTSD rate from this survey.

Fourth, the survey found that the female teachers reported more sleep disturbance, depression or somatic discomfort. This is consistent with the results of previous studies $(18,31-33)$. Research found that the periodic changes of estradiol and progesterone in women may make them more prone to some emotional problems $(31,34)$. Teachers over 45 years old are more likely to have moderate to severe somatic discomfort and anxiety, which may be related to the initial epidemic report that the middle-aged and elderly are more vulnerable to the coronavirus. The result again alerted these two groups worthy of more mental health attention.

The study also found teachers with higher degrees and university teachers are most vulnerable to various psychological symptoms. This may be related to the professional characteristics of these two groups. Previous studies have shown that Chinese university teachers are generally enduring higher level of stress due to research requirement, pressure of promotion, and lack of adequate rest. Long-term stress is associated with poor sleep and can also reduce an individual's sense of self-efficacy (35). It can cause individuals to be more susceptible to negative 
environmental impact, make them more likely to have negative subjective experience during the COVID-19 pandemic.

In China, the interest in seeking mental health help is largely hindered by many factors including strict social norms, cultural beliefs, stigma, mental health literacy, etc. (36-38). People with higher level of education are more likely to seek professional help $(39,40)$. We hypothesized that our study population, with higher education than average citizens, may have better attitudes toward mental health help. With an overarching aim to build an effective psychological support system for teachers during and after the pandemic, we listed four commonly used and practically implementable interventions for the participants to choose. Multiple selections were allowed. We found men teachers are more likely to choose psychological material reading and online counseling, and women teachers are more likely to choose practicing stress management skills. Teachers aged 26-35 prefer telephone hotlines and online counseling. This age group did not report higher rate of severe mental health symptoms. Their desire to seek telephone or online help may be associated with their acceptance of and familiarity with high technology. Middle/high school teachers are more likely to choose psychological materials and hotline service. Even if the underlying reason is unknown, we should consider providing more related education to middle/high schools during and past the pandemic.

We are not surprised to see that teachers with moderate to severe mental problems are more likely to seek help. Perceived high level of psychological distress may increase treatment seeking behavior. Even though majority of teachers tend not to choose telephone hotline as a way for help, those with serious self-harm and suicidal thoughts are more willing to use this method. This is encouraging because only through hotline can emergent help be achieved. Previous studies have shown that online screening may enhance decisions to seek professional help (41). We hope that this large-scale survey will increase public awareness of mental health concerns in teachers. A follow-up data showed that by the time of this manuscript, the psychological materials we provided during and after this survey has reached 341,539 electronic downloads, 5,155 online audios listening and 4,003 video views. Our hotline has received 762 calls between January 31 and April 6. This is a clear manifestation of mental health demand during the COVID-19 pandemic. We've learned that many teachers suffer from psychological symptoms that warrant different levels of intervention, and majority indicated that they needed more than one way of psychological assistance.

This study has strengths and limitations. First, this is a large-scale survey with a very high response. Second, we used several standardized instruments to investigate multiple aspects of teacher's mental health condition. Third, this is a timely research on a special population during COVID-19 pandemic. At the time of this manuscript, COVID-19 transmission has been better controlled but continues to be a global health emergency. Businesses and schools are reopening in many places. This study can be used as a reference in public mental health strategic planning and rapid deployment of effective mental health interventions. Limitations include, first, it is a cross sectional study so limited to a single time point. We were not able to do a pre- and-post COVID-19 comparison of the psychological distress of teachers. Second, this survey is targeted to teachers who generally have high level of education. The teaching requirements, expectations from students and parents, modal of remote education can vary from place to place. Therefore, many confounding factors existed so the study result may not be generalizable to a different population in other countries during the COVID-19 outbreak. Third, considering that the length of the questionnaire may affect the respondent's compliance with the questionnaire, we only use a single item to ask about sleep disorders. This item was previously used to screen for sleep problems in cancer patients, but it lacks the reliability test of the teacher population.

\section{CONCLUSIONS}

This study investigated the mental health condition of Chinese teachers during the COVID-19 outbreak. The survey found that the major reported psychological distresses are anxiety, sleep disturbance, and somatic symptoms. Small number of teachers reported depression and post-traumatic stress. Some had thoughts of self-injury or suicide. There were gender, age and school setting differences. Females over 45 years old and university teachers were more vulnerable to various mental problems. Different individuals have different preferences for intervention methods, mostly based on the type and severity of their symptoms.

\section{DATA AVAILABILITY STATEMENT}

The raw data supporting the conclusions of this article will be made available by the authors, without undue reservation.

\section{ETHICS STATEMENT}

The studies involving human participants were reviewed and approved by the Ethics Committee of the Second Xiangya Hospital of Central South University. The patients/participants provided their written informed consent to participate in this study.

\section{AUTHOR CONTRIBUTIONS}

$\mathrm{XL}$ and CP: data collection, literature review, and manuscript drafting. WX and LW: managed the ethical review process. ZW, $\mathrm{XS}$, LL, and ZL: manuscript drafting and revision. All authors read and approved the final manuscript.

\section{FUNDING}

This study was supported by Hunan Key Research and Development Program (No. 2018SK2136) and Hunan Provincial Natural Science Foundation of China (No. 2018JJ2592). These funds had no role in the design of this study, in the collection, analysis and interpretation of data, in the writing of the report, and in the decision to submit the paper for publication. 


\section{REFERENCES}

1. Brug J, Aro AR, Oenema A, Zwart O, d., Richardus JH, et al. SARS risk perception, knowledge, precautions, information sources. The Netherlands. Emerg Infect Dis. (2004) 10:1486-9. doi: 10.3201/eid1008.040283

2. Meo SA, Alhowikan AM, Al-Khlaiwi T, Meo IM, Halepoto DM, Iqbal M, et al. Novel coronavirus 2019-nCoV: prevalence, biological and clinical characteristics comparison with SARS-CoV and MERS-CoV. Eur Rev Med Pharmacol Sci. (2020) 24:2012-9. doi: 10.26355/eurrev_202002_20379

3. Mihashi $M$, Otsubo $Y$, Yinjuan $X$, Nagatomi $K$, Hoshiko $M$, Ishitake T. Predictive factors of psychological disorder development during recovery following SARS outbreak. Health Psychol. (2009) 28:91-100. doi: 10.1037/a0013674

4. Laybourn S, Frenzel AC, Fenzl T. Teacher procrastination, emotions, and stress: a qualitative study. Front Psychol. (2019) 10:2325. doi: 10.3389/fpsyg.2019.02325

5. Kidger J, Gunnell D, Biddle L, Campbell R, Donovan J. Part and parcel of teaching? Secondary school staff's views on supporting student emotional health and well-being. Br Educ Res J. (2009) 36:919-35. doi: 10.1080/01411920903249308

6. Kroenke K, Spitzer RL, Williams JB, Lowe B. The patient health questionnaire somatic, anxiety, and depressive symptom scales: a systematic review. Gen Hosp Psychiatry. (2010) 32:345-59. doi: 10.1016/j.genhosppsych.2010.03.006

7. Spitzer RL, Kroenke K, Williams JBW, Löwe B. A brief measure for assessing generalized anxiety disorder the GAD 7. Arch Intern Med. (2006) 166:10927. doi: $10.1001 /$ archinte.166.10.1092

8. Kroenke K, Spitzer RL, Williams JBW, Monahan PO, Löwe B. Anxiety disorders in primary care prevalence, impairment, comorbidity, and detection. Ann Intern Med. (2007) 146:31725. doi: 10.7326/0003-4819-146-5-200703060-00004

9. Zijlema WL, Stolk RP, Löwe B, Rief W, White PD, Rosmalen JGM. How to assess common somatic symptoms in large-scale studies: a systematic review of questionnaires. J Psychosom Res. (2013) 74:45968. doi: 10.1016/j.jpsychores.2013.03.093

10. Prins A, Bovin MJ, Smolenski DJ, Marx BP, Kimerling R, Jenkins-Guarnieri MA, et al. The primary care PTSD screen for DSM-5 (PC-PTSD-5): development and evaluation within a veteran primary care sample. J Gen Intern Med. (2016) 31:1206-11. doi: 10.1007/s11606-016-3703-5

11. Schulte T, Hofmeister D, Mehnert-Theuerkauf A, Hartung T, Hinz A. Assessment of sleep problems with the Insomnia Severity Index (ISI) and the sleep item of the Patient Health Questionnaire (PHQ-9) in cancer patients. Support Care Cancer. (2021). doi: 10.1007/s00520-021-06282-x. [Epub ahead of print].

12. Wunsch-Hitzig R, Plapinger J, Draper J, Campo ED. Calls for help after September 11 a community mental health hot line. J Urban Health. (2002) 79:417-28. doi: 10.1093/jurban/79.3.417

13. Marres GM, Leenen LP, van der Slikke JW, Vermetten E. Use of a web portal for support and research after a disaster: opportunities and lessons learned. Interact J Med Res. (2012) 1:e18. doi: 10.2196/ijmr.1588

14. Stachteas P, Stachteas C. The psychological impact of the COVID19 pandemic on secondary school teachers. Psychiatriki. (2020) 31:293301. doi: $10.22365 /$ jpsych.2020.314.293

15. Lin TY. Psychiatry and Chinese culture. West J Med. (1983) 139:862-7.

16. Ryder A, Yang J, Zhu X, Yao S, Yi J, Heine S, et al. The cultural shaping of depression: somatic symptoms in China, psychological symptoms in North America? J Abnorm Psychol. (2008) 117:300-13. doi: 10.1037/0021-843X.117.2.300

17. Kocalevent RD, Hinz A, Brähler E. Standardization of a screening instrument (PHQ-15) for somatization syndromes in the general population. BMC Psychiatry. (2013) 13:91. doi: 10.1186/1471-244X-13-91

18. Leung GM, Ho, L.-M., Chan SKK, Ho, S.-Y., et al. Longitudinal assessment of community psychobehavioral responses during and after the 2003 outbreak of severe acute respiratory syndrome in Hong Kong. Clin Infect Dis. (2005) 40:1713-20. doi: 10.1086/42 9923

19. Goulia P, Mantas C, Dimitroula D, Mantis D, Hyphantis T. General hospital staff worries, perceived sufficiency of information and associated psychological distress during the A H1N1 influenza pandemic. BMC Infect Dis. (2010) 10:322. doi: 10.1186/1471-2334-10-322

20. Hiller W, Rief W, Brähler E. Somatization in the population: from mild bodily misperceptions to disabling symptoms. Soc Psychiatry Psychiatr Epidemiol. (2006) 41:704-12. doi: 10.1007/s00127-006-0082-y

21. Hanel G, Henningsen P, Herzog W, Sauer N, Schaefert R, Szecsenyi J, et al. Depression, anxiety, and somatoform disorders: vague or distinct categories in primary care? Results from a large cross-sectional study. J Psychosom Res. (2009) 67:189-97. doi: 10.1016/j.jpsychores.2009.04.013

22. Byrne EM, Timmerman A, Wray NR, Agerbo E. Sleep disorders and risk of incident depression: a population case-control study. Twin Res Hum Genet. (2019) 22:140-6. doi: 10.1017/thg.2019.22

23. Weaver MD, Vetter C, Rajaratnam SMW, O'Brien CS, Qadri S, Benca RM, et al. Sleep disorders, depression and anxiety are associated with adverse safety outcomes in healthcare workers: a prospective cohort study. J Sleep Res. (2018) 27:e12722. doi: $10.1111 /$ jsr.12722

24. Bernert RA, Kim JS, Iwata NG, Perlis ML. Sleep disturbances as an evidence-based suicide risk factor. Curr Psychiatry Rep. (2015) 17:554. doi: 10.1007/s11920-015-0554-4

25. Ered A, Cooper S, Ellman LM. Sleep quality, psychological symptoms, psychotic-like experiences. J Psychiatr Res. (2018) 98:95-8. doi: 10.1016/j.jpsychires.2017.12.016

26. Corfield EC, Martin NG, Nyholt DR. Co-occurrence and symptomatology of fatigue and depression. Compr Psychiatry. (2016) 71:1-0. doi: 10.1016/j.comppsych.2016.08.004

27. Hawryluck L, Gold WL, Robinson S, Pogorski S, Galea S, Styra R. SARS control and psychological effects of quarantine, Toronto, Canada. Emerg Infect Dis. (2004) 10:1206-12. doi: 10.3201/eid1007.030703

28. Fan C, Fu P, Li X, Li M, Zhu M. Trauma exposure and the PTSD symptoms of college teachers during the peak of the COVID-19 outbreak. Stress Health. (2021). doi: 10.1002/smi.3049. [Epub ahead of print].

29. McAlonan GM, Lee AM, Cheung V, Cheung C, Tsang KWT, Sham PC, et al. Immediate and Sustained Psychological Impact of an emerging infection disease outbreak on health care workers. Can J Psychiatry. (2007) 52:2417. doi: $10.1177 / 070674370705200406$

30. Singhal T. A review of coronavirus disease-2019 (COVID-19). Indian J Pediatr. (2020) 87:281-6. doi: 10.1007/s12098-020-03263-6

31. Altemus M, Sarvaiya N, Neill Epperson C. Sex differences in anxiety and depression clinical perspectives. Front Neuroendocrinol. (2014) 35:32030. doi: 10.1016/j.yfrne.2014.05.004

32. Bangasser DA, Eck SR, Telenson AM, Salvatore M. Sex differences in stress regulation of arousal and cognition. Physiol Behav. (2018) 187:4250. doi: 10.1016/j.physbeh.2017.09.025

33. Estrada-Munoz C, Vega-Munoz A, Castillo D, Muller-Perez S, BoadaGrau J. Technostress of chilean teachers in the context of the covid19 pandemic and teleworking. Int J Environ Res Public Health. (2021) 18:5458. doi: 10.3390/ijerph18105458

34. Sophie H Li BMG. Why are women so vulnerable to anxiety, trauma related and stress related disorders the potential role of sex hormones. Lancet Psychiatry. (2016) 4:73-82. doi: 10.1016/S2215-0366(16)30358-3

35. Skaalvik EM, Skaalvik S. Teacher self-efficacy and teacher burnout: a study of relations. Teach Teach Educ. (2010) 26:105969. doi: 10.1016/j.tate.2009.11.001

36. Li J, Zhang MM, Zhao L, Li WQ, Mu JL, Zhang ZH. Evaluation of attitudes and knowledge toward mental disorders in a sample of the Chinese population using a web-based approach. BMC Psychiatry. (2018) 18:367. doi: 10.1186/s12888-018-1949-7

37. Yu S, Kowitt SD, Fisher EB, Li G. Mental health in China: stigma, family obligations, and the potential of peer support. Community Ment Health J. (2018) 54:757-64. doi: 10.1007/s10597-017-0182-z

38. Huang D, Yang LH, Pescosolido BA. Understanding the public's profile of mental health literacy in China: a nationwide study. BMC Psychiatry. (2019) 19:20. doi: 10.1186/s12888-018-1980-8

39. Gong AT, Furnham A. Mental health literacy: public knowledge and beliefs about mental disorders in mainland China. PsyCh J. (2014) 3:144-158. doi: 10.1002/pc hj. 55 
40. Wu Q, Luo X, Chen S, Qi C, Long J, Xiong Y, et al. Mental health literacy survey of non-mental health professionals in six general hospitals in Hunan Province of China. PloS ONE. (2017) 12:e0180327. doi: 10.1371/journal.pone.0180327

41. Kim EH, Coumar A, Lober WB, Kim Y. Addressing mental health epidemic among university students via web-based, self-screening, and referral system: a preliminary study. IEEE Trans Inf Technol Biomed. (2011) 15:3017. doi: 10.1109/TITB.2011.2107561

42. Stephanie. Standardized Residuals in Statistics: What are They? (2013). Available online at: https://www.statisticshowto.datasciencecentral.com/ what-is-a-standardized-residuals/ (accessed March 20, 2021).
Conflict of Interest: The authors declare that the research was conducted in the absence of any commercial or financial relationships that could be construed as a potential conflict of interest.

Copyright (c) 2021 Lizhi, Peng, Wanhong, Shengmei, Lingjiang, Li, Xiaoping and Weihui. This is an open-access article distributed under the terms of the Creative Commons Attribution License (CC BY). The use, distribution or reproduction in other forums is permitted, provided the original author(s) and the copyright owner(s) are credited and that the original publication in this journal is cited, in accordance with accepted academic practice. No use, distribution or reproduction is permitted which does not comply with these terms. 